\title{
Optical Properties of Al- and Sb-Doped CdTe Thin Films
}

\author{
A. A. J. Al-Douri, ${ }^{1}$ F. Y. Al-Shakily, ${ }^{2}$ M. F. A. Alias, ${ }^{3}$ and A. A. Alnajjar1 \\ ${ }^{1}$ Applied Physics Department, Sciences College, University of Sharjah, P.O. Box 27272, Sharjah, UAE \\ ${ }^{2}$ Physics Department, Education College, Al-Mustansirya University, Baghdad, Iraq \\ ${ }^{3}$ Physics Department, Science College, University of Baghdad, P.O. Box 47162, Jadiriyah Baghdad, Iraq \\ Correspondence should be addressed to A. A. J. Al-Douri, douri@sharjah.ac.ae \\ Received 5 September 2009; Accepted 27 January 2010 \\ Academic Editor: Gayanath Fernando
}

Copyright (c) 2010 A. A. J. Al-Douri et al. This is an open access article distributed under the Creative Commons Attribution License, which permits unrestricted use, distribution, and reproduction in any medium, provided the original work is properly cited.

\begin{abstract}
Nondoped and (Al, Sb)-doped CdTe thin films with 0.5, 1.5, and 2.5 wt.\%, respectively, were deposited by thermal evaporation technique under vacuum onto Corning 7059 glass at substrate temperatures $\left(T_{s}\right)$ of room temperature $(\mathrm{RT})$ and $423 \mathrm{~K}$. The optical properties of deposited CdTe films such as band gap, refractive index $(n)$, extinction coefficient $\left(k_{e}\right)$, and dielectric coefficients were investigated as function of $\mathrm{Al}$ and $\mathrm{Sb}$ wt.\% doping, respectively. The results showed that films have direct optical transition. Increasing $T_{s}$ and the wt.\% of both types of dopant, the band gap decrease but the optical is constant as $n, k_{e}$ and real and imaginary parts of the dielectric coefficient increase.
\end{abstract}

\section{Introduction}

Semiconductor materials like II-VI have found their way in many applications such as photovoltaic and photoconductive devices $[1,2]$. Heterojunctions (HJs) have attracted intensive research interest over the last four decades [3, 4] because of their potential importance in many technological applications. Cadmium telluride (CdTe) is unique among II-VI compounds which makes it important and quite suitable for several applications as it may exhibit both $\mathrm{n}$ - and p-types conductivity. It is one of the few II-VI compounds that are usually used as absorbers for photovoltaic devices [5]. It is band gap of $1.5 \mathrm{eV}$, just in the middle of the solar spectrum, and processes high absorption coefficient $(\alpha)\left(>10^{4} \mathrm{~cm}^{-1}\right)$ for the visible solar spectrum [6]. One of the advantages of this material is the possibility to vary its band gap with various dopant concentrations [7].

Considerable change in optical, electrical, and mechanical properties of CdTe thin films is produced by doping. Moreover p-type and n-type doping of CdTe is easy to achieve. The elements of the first and fifth columns of the periodic table act as acceptors, and those of the third and seventh columns act as donors. Mainly $\mathrm{Al}, \mathrm{Ga}, \mathrm{In}, \mathrm{I}$, and $\mathrm{Cl}$ have been used as donors, and $\mathrm{Li}, \mathrm{Cu}, \mathrm{Ag}, \mathrm{N}, \mathrm{P}, \mathrm{Sb}$, and $\mathrm{As}$ as acceptors. Some of these elements show special behavior in
CdTe, depending on the site they occupy in the crystalline lattice [8-15]. The maximum doping levels achievable in bulk CdTe are of around $10^{17} \mathrm{~cm}^{-3}$ for holes (As, P, and Li), and about $10^{18} \mathrm{~cm}^{-3}$ for electrons (Al, I, and In) [15].

The purpose of the present paper is to study the effect of substrate temperatures and doping percentages of $\mathrm{Al}$ and $\mathrm{Sb}$ on the optical properties of CdTe thin films. This study covered the optical energy gap, refractive index, extinction coefficient, and real and imaginary parts of dielectric constants for the prepared films.

\section{Experimental Procedure}

The films of CdTe are deposited by thermal evaporation technique under $10^{-6}$ Torr vacuum pressure using the Edward E306A coating system. Different deposition conditions were introduced to prepare the films such as substrate temperatures $\left(T_{s}\right)$ at RT and $423 \mathrm{~K}$ and dopant weight percentage $(0.5,1.5$, and 2.5$)$ of $5 \mathrm{~N}$ purity of Al for $\mathrm{n}$-type and $\mathrm{Sb}$ for $\mathrm{p}$ type thin film. A high purity (99.999\%) of CdTe powder from Balzer was used as a source for undoped and doped CdTe thin films deposition using molybdenum boat. The films which thickness is about $0.5 \mu \mathrm{m}$ were grown on Corning glass substrate 7059 with a size of $1.0 \times 2.5 \mathrm{~cm}^{2}$. The substrate 
was cleaned in a detergent, boiled in deionized water, and finally cleaned by using ultrasonic with isopropyl alcohol. After being dried, they were put at $20.0 \mathrm{~cm}$ distance from the evaporator source. The substrate temperature was measured and controlled using digital thermometer. The growth rate was controlled by keeping the sources temperature constant within $\pm 5 \%$ and the deposition rate was maintained as $0.0385 \mu \mathrm{m} / \mathrm{min}$. The thickness of the films was determined by optical interferometer method. The composition of the prepared films was determined using energy dispersive X-ray analysis (EDX) with the use of a Jeol JSM5600 equipment. The EDX scans results coincide with theoretical percentage values of $\mathrm{CdTe}, \mathrm{Al}$ and, $\mathrm{Sb}$ in undoped and doped CdTe thin film [16].

Optical transmittance spectra of undoped and doped CdTe thin films with different wt.\% of $\mathrm{Al}$ and $\mathrm{Sb}$ were carried out at RT using Perkin-Elmer Lambda800-UV-VIS spectrophotometer connected with Phillips computer. The absorption coefficient $(\alpha)$, energy gap $\left(E_{g}\right)$ and optical constants such as refractive index $(n)$, extinction coefficient $\left(k_{e}\right)$, and the real and imaginary $\left(\varepsilon_{r} \& \varepsilon_{i}\right)$ parts of dielectric constants of thin films were calculated.

\section{Results and Discussion}

There is a wide agreement among the researchers that the optimum approach for the determination of the optical band gap of the compound semiconductor, such as CdTe thin films, is to calculate the absorption spectra of the samples through the measurement of their transmission intensity [17].

Figures 1(a) and 1(b) show the results of such optical transmission spectrum ( $\lambda$ from 0.5 to $0.9 \mu \mathrm{m}$ ) for the undoped and doped CdTe films with 2.5\% $\mathrm{Al}$ and $2.5 \%$ $\mathrm{Sb}$ deposited on glass substrate at substrate temperature of RT and $423 \mathrm{~K}$, respectively. The spectral behavior of these films shows that the absorption edges shift to higher wavelength (lower photon energy) for films deposited at RT and $423 \mathrm{~K}$ after doping with $\mathrm{Al}$ and $\mathrm{Sb}$. This indicates that the doped films have lower band gap value compared to that for undoped films. Another noticeable remark is that the transmissions for films doped with $2.5 \% \mathrm{Sb}$ were lower than those of undoped and 2.5\% Al-doped films for both deposition substrate temperatures. Also it should be noted from Figures 1(a), 1(b) that the transmission near the band edge is higher for the undoped CdTe thin film deposited at $423 \mathrm{~K}$ than that deposited at RT. This behavior can be attributed to the improvement in perfection of the film quality [18], and this result is in agreement with the result reported by Basol [19].

From the transmittance data and according to Tauc relation [20], $(\alpha E)^{2}$ versus incident photon energy (E) plots were obtained, and the graphs are presented in the inset of Figures 1(a) and 1(b). All the plots have shown straight line regions where $\alpha \geq 10^{4} \mathrm{~cm}^{-1}$ indicates that $\mathrm{CdTe}$ has a direct allowed band gap material. This behavior is in agreement with other researchers [21-23], while Rasheed [24] had indicated that the transition in CdTe is indirect. Several

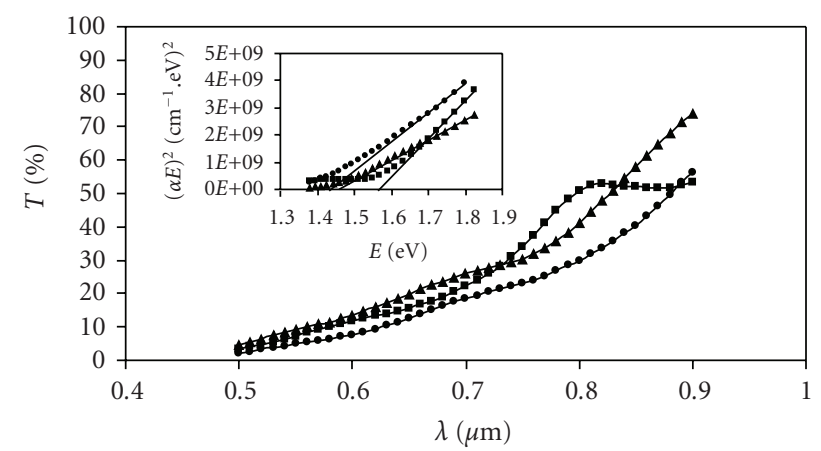

(a)

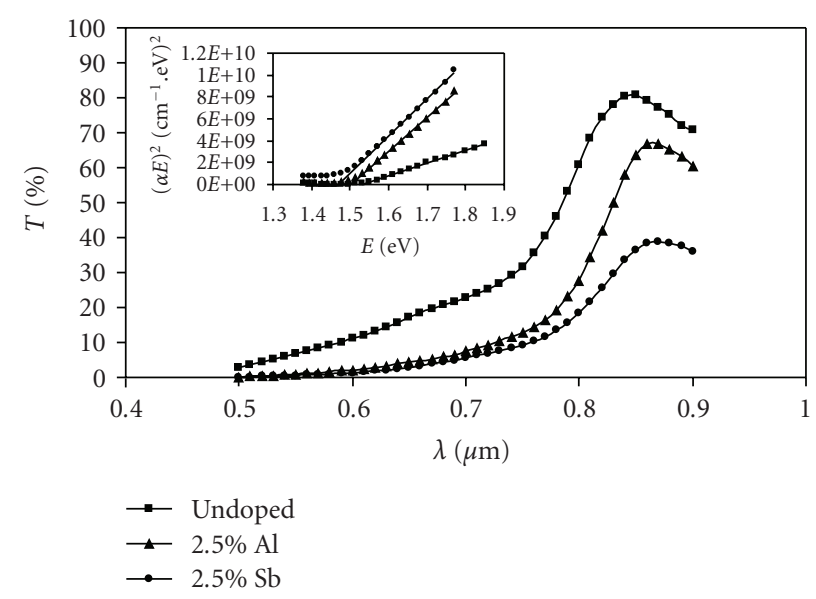

(b)

Figure 1: (a), (b) Transmission spectra of undoped and doped CdTe thin films with $2.5 \% \mathrm{Al}$ and $2.5 \% \mathrm{Sb}$ deposited on glass substrate at (a) RT and (b) $423 \mathrm{~K}$. The inset shows $(\alpha E)^{2}$ versus $E$.

authors have observed direct and indirect optical transitions in CdTe thin films $[25,26]$. This controversy in published data for $E_{g}$ might be due to the variation in preparation techniques and deposition parameters.

The band gap energy $\left(E_{g}\right)$ has been determined by intercepting the linear portion of the absorption curves to the photon energy axis for zero absorption coefficient $(\alpha=0)$; the values of $E_{g}$ are listed in Table 1. These results showed that $E_{g}$ is depending on $T_{s}$ and doping concentration for both $\mathrm{Al}$ and $\mathrm{Sb}$. Figure 2 illustrates the variation of $E_{g}$ with doping percentage concentrations of $\mathrm{Al}$ and $\mathrm{Sb}$ for $\mathrm{CdTe}$ thin films deposited at RT and $423 \mathrm{~K}$. From Figure 2 and data in Table 1 it is show that the value of $E_{g}$ for undoped CdTe deposited at RT is higher than that deposited at $423 \mathrm{~K}$. Similar behavior was reported by Saha et al. [25] for flash evaporated CdTe thin films. The decrease in $E_{g}$ with $T_{s}$ for undoped CdTe can be attributed to crystallinity improvement of films deposited at high substrate temperature. These in turn make a shift of the film band gap towards a bulk $E_{g}$ value of CdTe that is, $1.51 \mathrm{eV}$. Also it can be seen that upon doping with $0.5 \mathrm{wt} \%$ $\mathrm{Al}, E_{g}$ decreases from $1.57 \mathrm{eV}$ to $1.54 \mathrm{eV}$ at $\mathrm{RT}$ and from $1.54 \mathrm{eV}$ to $1.52 \mathrm{eV}$ at $423 \mathrm{~K}$, whereas it decreases from $1.57 \mathrm{eV}$ to $1.53 \mathrm{eV}$ at RT and from $1.54 \mathrm{eV}$ to $1.50 \mathrm{eV}$ at $423 \mathrm{~K}$ for 
TABLE 1: Values of $E_{g}, k_{e}, n, \varepsilon_{r}$, and $\varepsilon_{i}$ for undoped and doped CdTe thin films deposited with $T_{s}=\mathrm{RT}$ and $423 \mathrm{~K}$ at $\lambda=0.82 \mu \mathrm{m}$.

\begin{tabular}{|c|c|c|c|c|c|c|}
\hline CdTe thin film & $T_{s}$ & $E_{g}$ & $k_{e}$ & $n$ & $\varepsilon_{r}$ & $\varepsilon_{i}$ \\
\hline \multirow{2}{*}{ Undoped } & $\mathrm{RT}$ & 1.57 & 0.069 & 2.559 & 6.544 & 0.353 \\
\hline & 423 & 1.54 & 0.062 & 2.588 & 6.694 & 0.321 \\
\hline \multicolumn{7}{|l|}{ Doped with } \\
\hline \multirow{2}{*}{$0.5 \% \mathrm{Al}$} & $\mathrm{RT}$ & 1.54 & 0.070 & 2.565 & 6.574 & 0.359 \\
\hline & 423 & 1.52 & 0.085 & 2.599 & 6.747 & 0.442 \\
\hline \multirow{2}{*}{$1.5 \% \mathrm{Al}$} & $\mathrm{RT}$ & 1.49 & 0.072 & 2.614 & 6.828 & 0.376 \\
\hline & 423 & 1.51 & 0.087 & 2.607 & 6.789 & 0.454 \\
\hline \multirow{2}{*}{$2.5 \% \mathrm{Al}$} & $\mathrm{RT}$ & 1.46 & 0.096 & 2.699 & 7.275 & 0.518 \\
\hline & 423 & 1.50 & 0.103 & 2.636 & 6.938 & 0.543 \\
\hline \multirow{2}{*}{$0.5 \% \mathrm{Sb}$} & RT & 1.53 & 0.084 & 2.625 & 6.884 & 0.441 \\
\hline & 423 & 1.50 & 0.094 & 2.631 & 6.913 & 0.495 \\
\hline \multirow{2}{*}{$1.5 \% \mathrm{Sb}$} & $\mathrm{RT}$ & 1.48 & 0.107 & 2.642 & 6.969 & 0.565 \\
\hline & 423 & 1.49 & 0.118 & 2.634 & 6.924 & 0.622 \\
\hline \multirow{2}{*}{$2.5 \% \mathrm{Sb}$} & RT & 1.44 & 0.135 & 2.704 & 7.293 & 0.730 \\
\hline & 423 & 1.47 & 0.160 & 2.649 & 6.992 & 0.848 \\
\hline
\end{tabular}

film doped with $0.5 \mathrm{wt} \% \mathrm{Sb}$. Upon increases the doping concentration to $2.5 \% \mathrm{Al}$ results in a decrease in $E_{g}$ to $1.46 \mathrm{eV}$ and $1.50 \mathrm{eV}$ for CdTe deposited at RT and $423 \mathrm{~K}$, respectively. Same trend behavior is observed for increasing the doping concentration to $2.5 \% \mathrm{Sb}$, that is, a decrease in $E_{g}$ to $1.44 \mathrm{eV}$ and $1.47 \mathrm{eV}$ for CdTe thin films deposited at RT and $423 \mathrm{~K}$ respectively. The decrease in $E_{g}$ with increasing the doping concentration is due to an increase of impurity states in the gap, which causing shifting Fermi level towards valence band energy (V.B) or conduction band energy (C.B) according to dopant type, and this contributes to make the deposited film possess a narrower value of optical energy gap $E_{g}$ [27]. A similar behavior has also been observed by Shehab [28] for CdTe doped with P and by Rusu [29] and Mohammed [30] for CdTe doped with Zn, while Nair et al. [31] have obtained a direct band gap of $1.42 \mathrm{eV}$ for both undoped and Sb-doped electrodeposited CdTe thin films.

In general $E_{g}$ value elevated with increasing $T_{s}$ for films doped with percentage concentration more than $0.5 \%$ for both types as shown in Figure 2.

The extinction coefficient $\left(k_{e}\right)$, refractive index $(n)$, and the real $\left(\varepsilon_{r}\right)$ and imaginary $\left(\varepsilon_{i}\right)$ parts of the dielectric constant for the prepared thin films have been estimated from reflectance $(R)$ data at $\lambda$ equal to $0.82 \mu \mathrm{m}$ using the following formula [32]:

$$
n=\left[\frac{4 R}{(R-1)^{2}}-k_{e}^{2}\right]^{1 / 2}-\frac{(R+1)}{(R-1)},
$$

where $k_{e}=\alpha \lambda / 4 \pi$.

The real and imaginary parts of the dielectric constant of the CdTe films were computed using the relation [33]

$$
\varepsilon_{r}=n^{2}-k_{e}^{2}, \varepsilon_{i}=2 n k_{e} .
$$

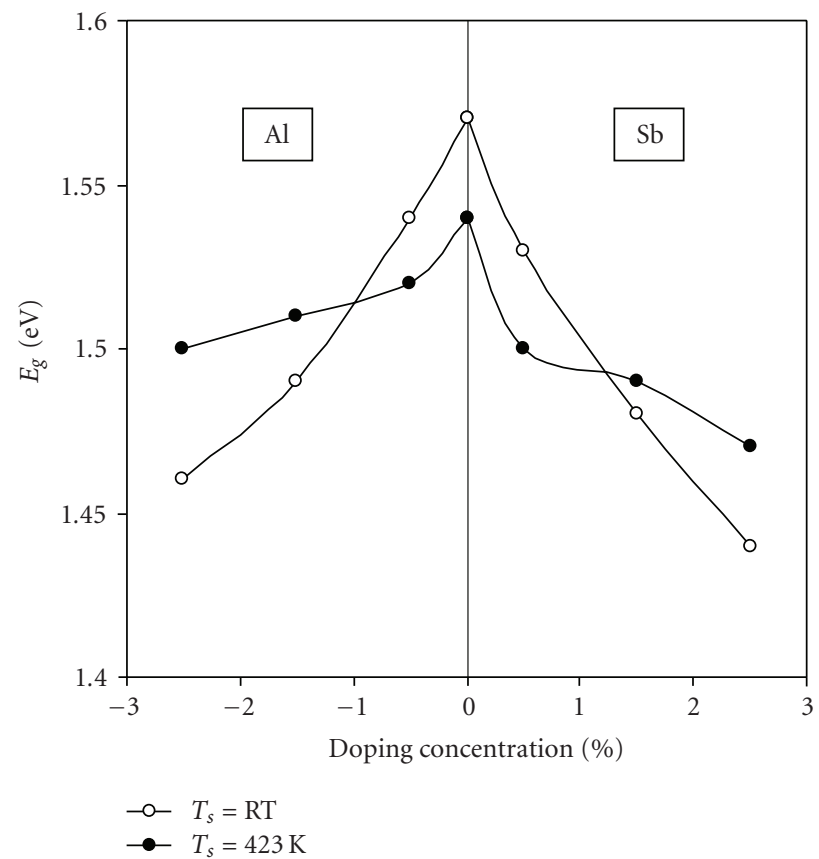

FIGURE 2: Variation of $E_{g}$ with dopant percentage concentrations of $\mathrm{Al}$ and $\mathrm{Sb}$.

The outcomes of these calculations are presented in Table 1. These results show that the values of $k_{e}$ and $\varepsilon_{i}$ are increased with increasing of $T_{s}$ and doping percentage concentration of $\mathrm{Al}$ and $\mathrm{Sb}$ except that they decreased with $T_{s}$ for undoped CdTe thin films. This behavior may be due to increase in absorption coefficient and it is in agreement with results shown by Saha et al. [25], while El-Shazly and El-Shair [34] showed that $k_{e}$ is almost constant and independent of the substrate temperature. 
The value of $n$ for undoped CdTe film deposited at $423 \mathrm{~K}$ is found to be greater than that deposited at RT as shown in Table 1 . The variation of $n$ with substrate temperature may be due to the variation of the crystallographic structure of the film with the substrate temperature [30]. This behavior is in agreement with those reported by Saha et al. [25] and El-Shazly and El-Shair [34]. Also, it, can be seen from Table 1 that $n$ for Al- and Sb-doped CdTe thin films deposited at RT and $423 \mathrm{~K}$ is greater than that for the corresponding undoped films which is in agreement with Saha et al. [25] for In-doped CdTe films. The data tabulated in Table 1 also shows that the value of $n$ is increased with increasing the concentration of both type of dopant $\mathrm{Al}$ and $\mathrm{Sb}$, but the trend of increase in $n$ for films doped with $\mathrm{Sb}$ is more than those doped with Al.

The variation of $\varepsilon_{r}$ with $T_{s}$ and doping concentration of both types of dopant $\mathrm{Al}$ and $\mathrm{Sb}$ are the same as of $n$ as shown in Table 1 because of the smaller value of $k_{e}^{2}$ compared with $n^{2}$.

\section{Conclusions}

Pure CdTe thin films as well as CdTe films doped with various percentages of $\mathrm{Al}$ and $\mathrm{Sb}$ were grown on the glass substrate using thermal evaporation technique. Film composition and deposition parameters were investigated for their bearing of film optical properties.

The following make the summary of the study.

(i) The films have allowed direct transition with optical energy gap lying within the range $1.44-1.57 \mathrm{eV}$.

(ii) Increasing in $T_{s}$ and dopant percentage concentrations for both $\mathrm{Al}$ and $\mathrm{Sb}$ caused a decrease in the optical band gap value.

(iii) There is increase in the optical constants $k_{e}$ and $n$ with increase in substrate temperature and doped percentage concentrations except for undoped CdTe thin film, where $k_{e}$ decreases with increasing $T_{s}$, and the variation of $\varepsilon_{r}$ and $\varepsilon_{i}$ have similar trend as for $n$ and $k_{e}$, respectively.

\section{References}

[1] P. Capper, Ed., Narrow Gap II-VI Compounds for Optoelectronic and Electromagnetic Applications, Chapman \& Hall, London, UK, 1st edition, 1997.

[2] N. Lovergine, P. Prete, L. Tapfer, F. Marzo, and M. Mancini, "Hydrogen transport vapour growth and properties of thick CdTe epilayers for RT X-ray detector applications,” Crystal Research and Technology, vol. 40, no. 10-11, pp. 1018-1022, 2005.

[3] F. Yu, "Structure of the $\mathrm{CdTe} / \mathrm{Cd}_{0.959} \mathrm{Zn}_{0.041} \mathrm{Te}$, $\mathrm{Hg}_{1-x} \mathrm{Cd}_{x} \mathrm{Te} / \mathrm{CdTe}, \mathrm{CdTe} / \mathrm{GaAs}$ heterojunctions," Journal of Crystal Growth, vol. 205, no. 3, pp. 264-269, 1999.

[4] A. Luque and S. Hegedus, Eds., Handbook of Photovoltaic Science and Engineering, John Wiley \& Sons, Sussex, UK, 2005.

[5] A. Morales-Acevedo, "Thin film CdS/CdTe solar cells: research perspectives," Solar Energy, vol. 80, no. 6, pp. 675-681, 2006.

[6] D. Lane, "A review of the optical band gap of thin film $\mathrm{CdS}_{x} \mathrm{Te}_{1-x}$," Solar Energy Materials and Solar Cells, vol. 90, no. 9, pp. 1169-1175, 2006.
[7] H. Scheel and T. Fukuda, Crystal Growth Technology, John Wiley \& Sons, Sussex, UK, 2003.

[8] A. L. Fahrenbruch, "Ohmic contacts and doping of CdTe," Solar Cells, vol. 21, no. 1-4, pp. 399-412, 1987.

[9] Y. Y. Loginov, P. D. Brown, K. Durose, et al., "Transmission electron microscopic studies of n- and p-type doped CdTe," Journal of Crystal Growth, vol. 117, no. 1-4, pp. 259-265, 1992.

[10] A. Alnajjar, S. Abdul Jawad, and N. Yusuf, "Investigation of ohmic contact to P-type CdTe:p using ac and dc techniques," Renewable Energy, vol. 27, no. 3, pp. 417-425, 2002.

[11] K. Yasuda, Y. Tomita, Y. Masuda, et al., "Growth condition of iodine-doped $\mathrm{n}^{+}$-CdTe layers in metal-organic vapor phase epitaxy," Journal of Electronic Materials, vol. 31, no. 7, pp. 785790, 2002.

[12] H. Scheel and T. Fukuda, Crystal Growth Technology, John Wiley \& Sons, New York, NY, USA, 2003.

[13] S. Shanmugan, S. Balaji, and D. Mutharasu, "Synthesis and characterization of $10 \% \mathrm{Sb}$ doped CdTe thin films by stacked elemental layer (SEL) method," Materials Letters, vol. 63, no. 13-14, pp. 1189-1191, 2009.

[14] C. M. Ruiz, O. Vigil, E. Saucedo, G. Contreras-Puente, and V. Bermúdez, "Bi doped CdTe: increasing potentialities of CdTe based solar cells," Journal of Physics Condensed Matter, vol. 18, no. 31, pp. 7163-7169, 2006.

[15] L. Jin, Y. Linyu, J. Jikang, Z. Hua, and S. Yanfei, "Effects of Sn-doping on morphology and optical properties of CdTe polycrystalline films," Journal of Semiconductors, vol. 20, no. 11, Article ID 112003, 4 pages, 2009.

[16] F. Al-Shakily, Characterization of CdTe/GaAs Heterojunction, Ph.D. thesis, College of Science, University of Baghdad, Baghdad, Iraq, 2009.

[17] S. Soundeswaran, O. S. Kumar, and R. Dhanasekaran, "Effect of ammonium sulphate on chemical bath deposition of CdS thin films," Materials Letters, vol. 58, no. 19, pp. 2381-2385, 2004.

[18] A. Ashour, "Physical properties of spray pyrolysed cds thin films," Turkish Journal of Physics, vol. 27, no. 6, pp. 551-558, 2003.

[19] B. M. Basol, "Electrodeposited CdTe and HgCdTe solar cells," Solar Cells, vol. 23, no. 1-2, pp. 69-88, 1988.

[20] J. Tauc, Amorphous and Liquid Semiconductors, Plenum Press, New York, NY, USA, 1974.

[21] I. Al-Asadi, The Study of the Relation of the Optical Constants of the CdTe Semiconductor with Thickness and Temperature Variations, M.S. thesis, College of Science, University of Baghdad, Baghdad, Iraq, 1998.

[22] L. R. Cruz and R. R. De Avillez, "Formation of CdTe thin films by the stacked elemental layer method," Thin Solid Films, vol. 373, no. 1-2, pp. 15-18, 2000.

[23] A. U. Ubale, R. J. Dhokne, P. S. Chikhlikar, V. S. Sangawar, and D. K. Kulkarni, "Characterization of nanocrystalline cadmium telluride thin films grown by successive ionic layer adsorption and reaction (SILAR) method," Bulletin of Materials Science, vol. 29, no. 2, pp. 165-168, 2006.

[24] M Rasheed, Study of the Effect of Preparation and Thickness Parameters on the Electrical and Optical Properties of CdTe Compound, M.S. thesis, College of Science, University of Baghdad, Baghdad, Iraq, 1993.

[25] S. Saha, U. Pal, A. K. Chaudhuri, V. V. Rao, and H. D. Banerjee, "Optical properties of CdTe thin films," Physica Status Solidi A, vol. 114, no. 2, pp. 721-729, 1989. 
[26] A. Abd El-Mongy, A. Belal, H. El Shaikh, and A. El Amin, "A comparison of the physical properties of CdTe single crystal and thin film," Journal of Physics D, vol. 30, no. 2, pp. 161-165, 1997.

[27] M. Alias, Optoelectronic Study of a-Si-Ge-Al (As): H Thin Films, Ph.D. thesis, College of Science, University of Baghdad, Baghdad, Iraq, 1998.

[28] A. Shehab, CdTe Solar Cells, M.S. thesis, College of Science, University of Baghdad, Baghdad, Iraq, 1985.

[29] G. Rusu, "Structural, electronic transport and optical properties of Zn-doped CdTe thin films," Journal of Optoelectronics and Advanced Materials, vol. 8, no. 3, pp. 931-935, 2006.

[30] H. Mohammed, Opto-Electronic Properties of CdTe:Zn Thin Films, M.S. thesis, College of Education -Ibn Al-Haithem, University of Baghdad, Baghdad, Iraq, 2008.

[31] J. Nair, R. Jayakrishnan, N. Chaure, and R. Pandey, "In situ Sbdoped CdTe films," Semiconductor Science and Technology, vol. 13, no. 3, pp. 340-344, 1998.

[32] A. Milnes and D. Feucht, Heterojunctions and Metal-Semiconductor Junctions, Academic Press, New York, NY, USA, 1972.

[33] L. Kazmerski, Polycrystalline and Amorphous Thin Films and Devices, Materials Science and Technology Series, Academic Press, New York, NY, USA, 1980.

[34] A. El-Shazly and H. El-Shair, "Some parameters affecting the optical constants of CdTe thin evaporated films," Thin Solid Films, vol. 78, no. 3, pp. 287-293, 1989. 

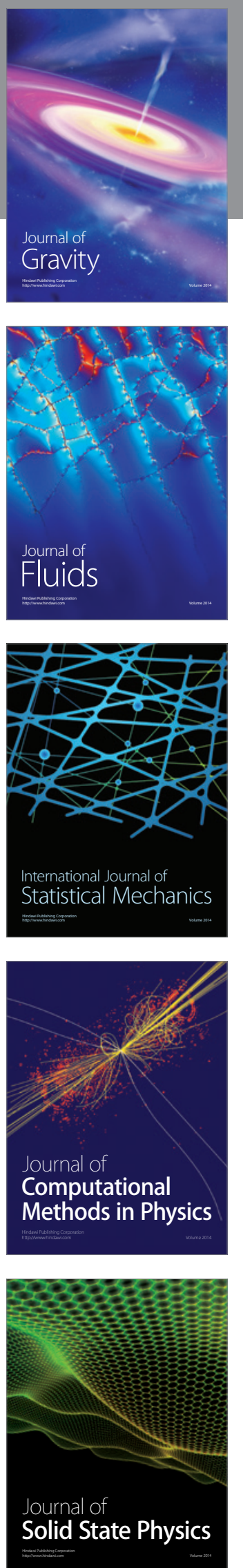

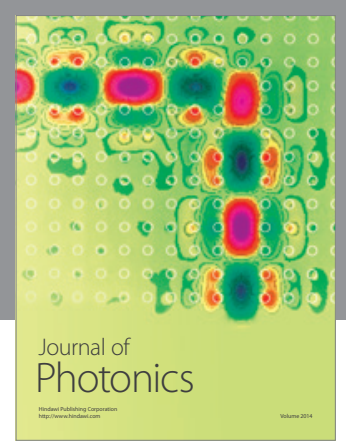

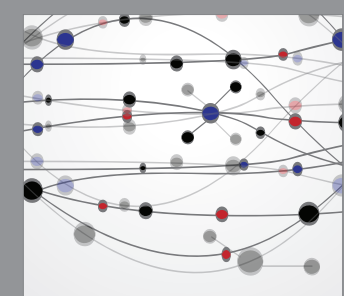

The Scientific World Journal
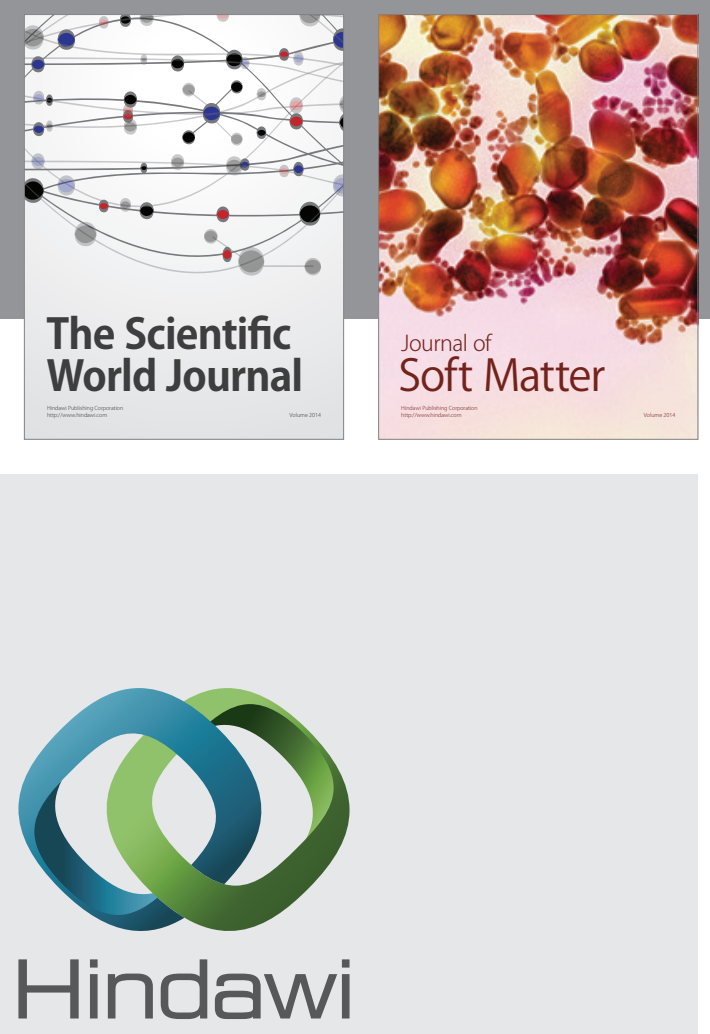

Submit your manuscripts at

http://www.hindawi.com
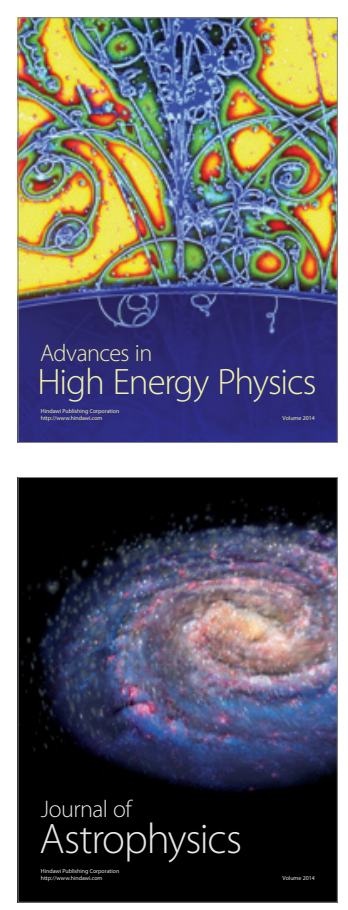
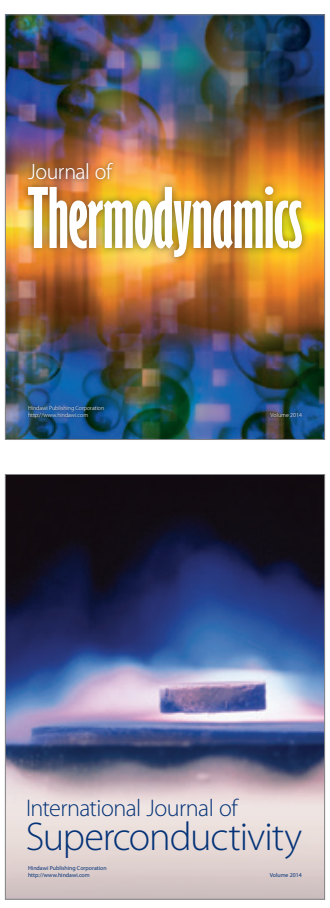
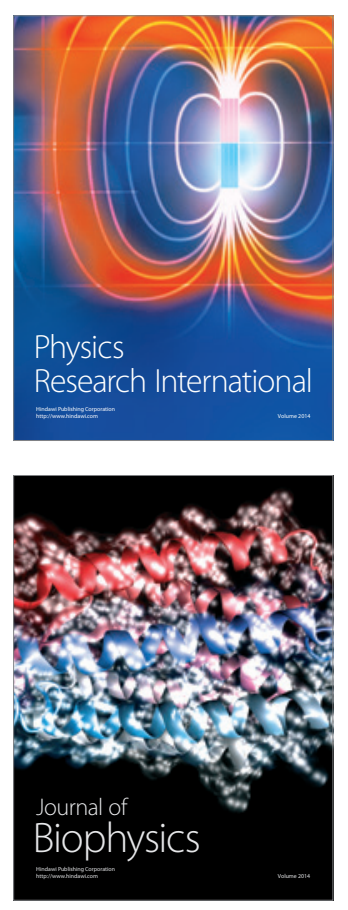
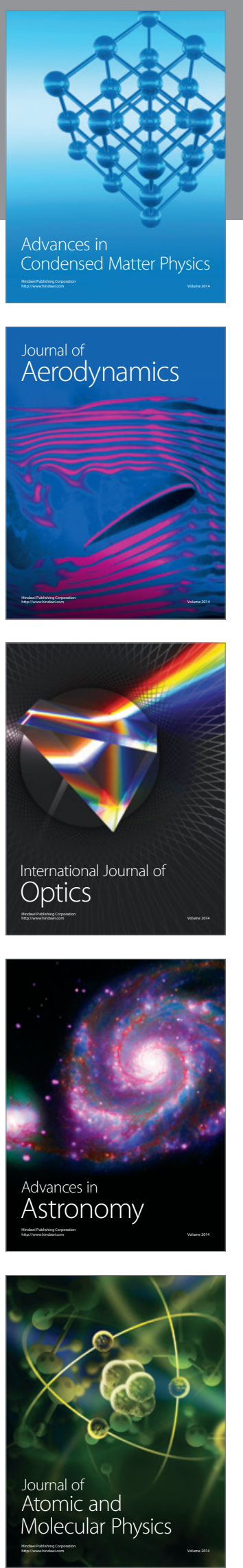